\title{
White Serum - A Clue to Diagnosis of Acute Recurrent Pancreatitis
}

\author{
Arghya Samanta $^{1} \cdot$ Anshu Srivastava $^{1}$ (D) $\cdot$ Sonali Verma ${ }^{2} \cdot$ Moinak Sen Sarma $^{1} \cdot$ Ujjal Poddar $^{1}$
}

Received: 17 June 2020 / Accepted: 4 September 2020 / Published online: 11 September 2020

(C) Dr. K C Chaudhuri Foundation 2020

To the Editor: Severe hypertriglyceridemia [serum triglyceride (TG) $>1000 \mathrm{mg} / \mathrm{dl}]$ is a rare cause of acute recurrent pancreatitis (ARP) [1]. We report a case of ARP caused by lipoprotein lipase (LPL) deficiency, successfully treated with insulin infusion.

A 4-y-old girl without any pre-existing systemic disease presented with recurrent episodes of epigastric pain and nonbilious vomiting for the past 6 mo with normalcy between the episodes. There was no history of jaundice, abdominal trauma, or drug intake. There was no history of consanguinity, dyslipidemia or pancreatitis in the family. On admission, she had tachycardia with otherwise unremarkable physical examination. Blood sampling showed white colored serum, with markedly elevated TG $(2451 \mathrm{mg} / \mathrm{dl})$ and total cholesterol of $343 \mathrm{mg} / \mathrm{dl}$. Serum amylase and lipase were $>3$ times of normal. Computed tomography of the abdomen showed bulky head of pancreas, 2 small intra-parenchymal fluid collections without changes of fatty liver or chronic pancreatitis. Lipid profile of parents was normal. The child was kept nil orally, given analgesics and insulin infusion (regular at $0.1 \mathrm{U} / \mathrm{kg} / \mathrm{h}$ ) along with dextrose infusion. The serum TG reduced to $330 \mathrm{mg} / \mathrm{dl}$ after $72 \mathrm{~h}$ with complete resolution of pain. Child was started on a low fat diet (10-15\% of total calories from fat and medium chain triglycerides being the main fat source) and insulin was stopped. However, epigastric pain recurred with increase in TG $(1108 \mathrm{mg} / \mathrm{dl})$ on $3 \mathrm{rd}$ day of stopping insulin. This settled with a second course of insulin infusion, with disappearance of pain within $24 \mathrm{~h}$ and reduction of TG $(885 \mathrm{mg} / \mathrm{dl}$ at $24 \mathrm{~h}, 354 \mathrm{mg} / \mathrm{dl}$ at $96 \mathrm{~h}$ ). This time, child was given omega-3 fatty acid, fenofibrate and niacin along with low-fat diet. Genetic testing

Anshu Srivastava

avanianshu@yahoo.com

1 Department of Pediatric Gastroenterology, Sanjay Gandhi Postgraduate Institute of Medical Sciences, Lucknow, Uttar Pradesh 226014, India

2 Department of Pediatric Endocrinology, Sanjay Gandhi Postgraduate Institute of Medical Sciences, Lucknow, Uttar Pradesh, India by exome sequencing confirmed homozygous c.644G $>$ A (p.Gly215Glu) LPL pathogenic variant [2]. At 4 months follow-up, serum TG was maintained below $400 \mathrm{mg} / \mathrm{dl}$, without recurrence of pancreatitis.

Supportive therapy and prompt reduction of TG is essential for hypertriglyceridemia related pancreatitis. But there are no established guidelines for the same in acute setting. Case reports have successfully used plasmapheresis, heparin or insulin in children [3-5]. Insulin (rapid activator of LPL), along with fasting, leads to rapid decline in TG and helps prevent life-threatening complications. LPL deficiency should be suspected in pancreatitis patients with white colored serum.

\section{Compliance with Ethical Standards}

Conflict of Interest None.

\section{References}

1. Scherer J, Singh VP, Pitchumoni CS, Yadav D. Issues in hypertriglyceridemic pancreatitis: an update. J Clin Gastroenterol. 2014;48:195-203.

2. Caddeo A, Mancina RM, Pirazzi C, et al. Molecular analysis of three known and one novel LPL variants in patients with type I hyperlipoproteinemia. Nutr Metab Cardiovasc Dis. 2018;28:158-64.

3. Poon SWY, Leung KKY, Tung JYL. Management of severe hypertriglyceridemia due to lipoprotein lipase deficiency in children. Endocrinol Diabetes Metab Case Rep. 2019;1:1-5.

4. Zhang KY, Cox KL, Sellers ZM. Plasmapheresis for hypertriglyceridemia-induced acute pancreatitis in a child: a case report and brief review of the literature. Pancreas. 2017;46:e58-9.

5. Berger Z, Quera R, Poniachik J, Oksenberg D, Guerrero J. Heparin and insulin treatment of acute pancreatitis caused by hypertriglyceridemia. Experience of 5 cases. Rev Med Chil. 2001;129:1373-8.

Publisher's Note Springer Nature remains neutral with regard to jurisdictional claims in published maps and institutional affiliations. 